\title{
Exploring Challenges Faced by Socially Responsible Companies in Oman
}

\section{Yasir Tabook, Sagaran Gopal, Sulochana Nair}

To Link this Article: http://dx.doi.org/10.6007/IJARBSS/v11-i10/10954

DOI:10.6007/IJARBSS/v11-i10/10954

Received: 09 August 2021, Revised: 01 September 2021, Accepted: 28 September 2021

Published Online: 04 October 2021

In-Text Citation: (Tabook et al., 2021)

To Cite this Article: Tabook, Y., Gopal, S., \& Nair, S. (2021). Exploring Challenges Faced by Socially Responsible Companies in Oman. International Journal of Academic Research in Business and Social Sciences, 11(10), 58-67.

\section{Copyright: @ 2021 The Author(s)}

Published by Human Resource Management Academic Research Society (www.hrmars.com)

This article is published under the Creative Commons Attribution (CC BY 4.0) license. Anyone may reproduce, distribute, translate and create derivative works of this article (for both commercial and non-commercial purposes), subject to full attribution to the original publication and authors. The full terms of this license may be seen at: http://creativecommons.org/licences/by/4.0/legalcode

\section{Vol. 11, No. 10, 2021, Pg. 58 - 67}

Full Terms \& Conditions of access and use can be found at http://hrmars.com/index.php/pages/detail/publication-ethics 


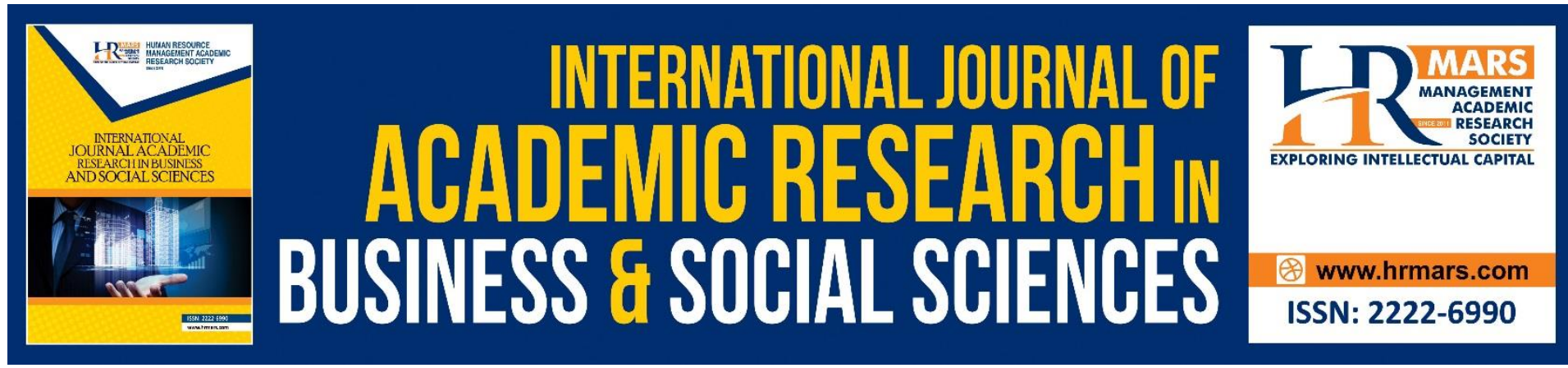

\title{
Exploring Challenges Faced by Socially Responsible Companies in Oman
}

\author{
Yasir Tabook, Sagaran Gopal, Sulochana Nair \\ Binary University of Management and Entrepreneurship, lol Business Park, NO. 1, 47100 \\ Puchong, Selangor, Malaysia
}

\begin{abstract}
The objective of this paper is to explore challenges facing CSR practitioner companies in Oman in order to develop a comprehensive understanding about the nature of those challenges and how it interact with each other. That understanding is important to improve the performance of socially responsible companies in Oman where CSR is yet to be practiced as a driver to sustainability. Data were collected using a qualitative approach relying on semi-structured interviews with CSR practitioner companies and the main stakeholders, and unstructured interviews with key informants. Data was coded and categorized in themes using Nvivo 12 Plus software. The findings indicated the presence of corporate-specific challenges that are related to the way companies recognize and practice CSR. Furthermore, the study identified a second group of CSR challenges that are collectively caused by the practitioner companies itself and multiple external stakeholders. The study highlighted the extent of negative influence that both groups of challenges place on the performances of socially responsible companies in Oman.
\end{abstract}

Keywords: Corporate Social Responsibility, Sustainability, Stakeholder Engagement, Corporate Culture, Oman.

\section{Introduction}

Corporate Social Responsibility projects play a strategic role in helping businesses to be seen as having an important impact on their communities and Oman is no exception. However, it has been observed that a large segment of national companies in Oman still feeling uncommitted to practice any real CSR or even philanthropic activities or totally disregard CSR, albeit to ensure minimum compliance with relevant laws (Zubaidi, personal interview, 2019). In contrast, there are many companies that have shown interests to practice CSR but lack the appropriate knowledge on how to set and manage its social or sustainability strategies (ibid). Nevertheless, there is a third group of companies that have launched its own CSR initiatives but remain unable to show any real cases of success out of its social activities (Busaidi, personal interview, 2019). This has raised questions on challenges hindering the advancement of CSR as a sustainability element by the practitioner companies in Oman and the relationships between those challenges which represents the aim of this paper. 


\section{Literature Review}

There are situations in which companies practicing CSR find itself unable to achieve or maintain business competitive advantages in the market through CSR applications overtime. This usually happen if these companies fail to strategically implement CSR policies, or if they are not flexible enough to allow the incorporation of organizational changes to operate as leading socially responsible enterprises (Prutina, 2015). This section highlights guidelines offered by previous studies on how socially responsible companies should behave to excel in its sustainability-oriented performances using CSR.

Among the implications of behaving as real socially responsible businesses is that companies have been urged to apply CSR as an integral part of the overall business strategy that is based on morals of ethics and respect to concerned stakeholders' claims in the business, as well as having significant potentials to meet the business mission and objectives (Mousiolis \& Zaridis, 2014). These companies' behaviour is insisted to remain coherent with their CSR principles in order to sustain corporate credibility and strategic commitment toward CSR, and also to meet society and stakeholders' expectations and gain their trust and support (Vveinhardta \& Zygmantaiteb, 2015). In fact, this trend was the foundation for another CSR approach as a function of organizational sustainability that had raisin by the end of twentieth century. According to that approach, CSR has been embedded into the business model as a long term strategy supported by a socially oriented organizational culture to simultaneously motivate social and environmental aspects; and to enhance companies' competitive capabilities (both financially and none financially) (Prutina, 2015). Thus, this approach has gained an international acceptance as CSR concept continues to interact efficiently with more new aspects toward the philosophy of sustainable development that flourished at the beginning of twenty first century (Goll \& Rasheed, 2004).

As a starting point toward sustainable CSR effects, Szczuka (2015) emphasized on the strategic application of CSR to rely on it as an effective tool enabling companies to capture innovation edges, concrete its competitive advantages, and achieve sustainable business development. This implies doing carful planning and prioritizing to resources allocated to CSR projects on a strategic basis taking into consideration the organizational objectives, values, and external market factors; all within the context of the existing social norms (Ralston, 2010). This concern necessities having effective CSR strategies in place to allow companies to gain the trust of some socially conscious stakeholders targeted by these companies such as customers and investors (Nollet, et al., 2016). Therefore, companies are challenged to develop solid commitment to CSR values that should be clearly articulated in organizational objectives and embedded into corporate strategies before practicing CSR activities (Shehadi, et al., 2013). Thus, when deciding to set and implement CSR strategies, companies have to ensure that they are fully aware of what CSR is all about, and acknowledge that they are prepared and flexible enough to respond to the implications of the CSR-related decisions they took on the business as well as on concerned stakeholders (Mousiolis \& Bourletidis, 2015).

Adopting a strategic approach for CSR requires a good understanding of corporate business environment as well as CSR principles and core issues. However, the existence of multidefinitions for CSR makes the process of implementing and measuring CSR strategically quite challenging, especially for companies with low CSR experience and/ or limited corporate capabilities (Shehadi, et al., 2013). For example, the theoretically proposed interaction between CSR and the triple bottom line becomes hardly identifiable in cases of ambiguous CSR values and/or CSR activities of broad scopes (Kim, et al., 2016). On a relevant finding 
Bowen (2007) revealed that a CSR strategy is much complex than a normal business strategy since CSR strategies require special capabilities for implementation different from those applied in the development of normal business strategies. That author based his argument on the behavioural aspect of the social strategy as a standard for companies to follow in order to sustain and motivate its social performance. That standard follows a set of complex procedures that many companies fail to accurately capture (ibid). However, there are some useful tactics for companies to adopt to efficiently overcome the aforementioned challenges. For instance, it is suitable to refer to Choi et al (2015) suggestion to conduct a SWOT analysis to identify the company's strengths that can be applied in CSR engagement and internal resources mobilization. Moreover, that analysis can help companies to set contingency plans to overcome organizational weaknesses hindering the social performance in one hand, and float research and development projects to uncover potential opportunities that social thinking can offer on the other hand. Likewise, the SWOT analysis can drive companies to become more innovative through motivating them to proactively control and redirect external threats on the corporate social environment.

In practice, such macro-micro analysis is found functional in helping companies to develop a comprehensive view of how their social strategies should be crafted, and how it can be successfully implemented to establish sustainable competitive advantages (Bowen, 2007). In this particular front, Shehadi et al (2013) highlighted the importance of leveraging corporate capabilities in the design of CSR initiatives implemented by companies. Those authors found that companies that strategically apply their own core competencies in the construction of their CSR agendas are more successful to attain their CSR goals and create social and environmental impact of high value. These companies tend to focus on key social or environmental issues that are most relevant to their expertise, industries, and core business rather than tackling irrelevant issues where they do not have any strong business capabilities. Furthermore, the authors pointed out that socially responsible companies should look beyond individual social initiative where they can best apply their competences and match those strengths to national development needs whenever possible to effectively contribute to achieving these goals through relevant CSR initiatives (ibid).

\section{The Methodology}

This paper adopted a qualitative multiple case study strategy to collect data from three different population groups in Oman (key informant individuals, companies with CSR activities, and stakeholder organizations). The data collection process commenced with conducting unstructured interviews with 6 key informants selected based on their expertise and/or experiences in CSR and sustainability field to direct the researcher on the main practical dimensions of the topic in the Omani case in general and the status of socially responsible companies and key concerned stakeholder organizations in particular. This was followed by semi-structured interviews with both 14 purposefully sampled CSR practitioner companies and 12 governments, semi-government, and NGO stakeholders had been pointed out by the key informants as well as some of the participant companies to be the most concerned stakeholders. The interviews' questioning focused on exploring and discussing the most important challenges faced by the practitioner companies and seek explanations for these challenges' nature, causes, relationships, impacts, and implications. Nvivo 12 plus software was used to analyze the data across the 3 participants' groups. The findings were reported across all the participants to capture a solid understanding about the challenges. 


\section{The Findings}

The findings reflected the existence of two types of challenges hindering the application of CSR as a driver to sustainability by the practitioner companies in Oman as follow:

\section{A. Common Challenges}

These challenges are shared between all concerned CSR stakeholders in the Omani context including the practitioner companies; and are grouped into four common challenges:

\section{Poor Awareness about CSR}

CSR as a concept still vague and miss-defined by many concerned stakeholders in Oman ( Shizawi, personal interview, 2019). This is mainly attributed to the weak awareness about CSR principles and core values among these players (Busaidi, personal interview, 2019). For instance, CSR is wrongly defined by government stakeholders and there is a confusion between CSR values and those of normal voluntarism work given the interrelations between both terms in certain extents. Therefore, these stakeholders don't realize that voluntarism is a self-driven motive for no return that is unnecessarily related to social or humanity morals despite the wide employment of voluntarism insights as a channel to communicate CSR values (Lawati, personal interview, 2019). There is also a confusion between CSR and philanthropies (Zubaidi, personal interview, 2019). This misunderstanding of CSR concept has been also reported for companies, NGOs, and the large community since many of these parties do not know how to differentiate between charities, donations, and CSR (Auffi, personal interview, 2019). The researcher concluded that the aforementioned poor awareness about CSR principles and values is the main cause of the majority of challenges facing CSR in Oman as will be discussed in different positions along this section.

Lack of relevant policies:

CSR polices, proper guidelines, and codes of best practices are missing in the Omani context (Al Zubaidi, personal interview, 2019). Only few companies with CSR practices rely on clear CSR polices, objectives and procedures it developed its own based on the understanding it has about CSR (Alawi, personal interview, 2019). However, the rest of CSR practitioners do not follow any proper governance systems or polices relevant to CSR that can help these companies to wisely manage its ethical responsibilities (ibid). This is reflected on sectoral scale where some sectors still poorly organized and lack governing polices related to its core businesses and to define the relationships between these companies and external stakeholders in the CSR or sustainability platform. Even many companies that showed commitment to support the community needs do not know how to do so in the lack of clarified procedures or governance systems organizing that process ( Rashdi, personal interview, 2019).

\section{Lack of partnership and collaboration between key players in the CSR arena}

The third common challenge reported for CSR in Oman was the lack of strategic collaboration or partnership between the CSR stakeholders in general (Lawati, personal interview, 2019). For instance, there is a clear gap in partnership between the government, NGOs and the private sector which ends up by distracting efforts, wasting time and financial resources. That lacked collaboration is also present among companies with CSR activities who prefer to work individual from each other. This has made many of the CSR projects implemented by these companies unorganized and sometimes none-directive (Busaidi, personal interview, 2019). 
For instance, companies other than those practicing CSR through social funds do not collaborate with each other to develop joint CSR projects where each company can employ its specialties or competencies to maximize the impact created by these investments on the community (Alawi, personal interview, 2019).

This absent collaboration and partnership is also present among the multiple governmental stakeholders in the CSR arena. These stakeholders have many agendas for CSR in the country and sometimes these agendas are conflicting or are basically duplicated efforts (Lawati, personal interview, 2019). This has made the collaboration between these stakeholders on CSR issues missing. Furthermore, the direct stakeholders who are working on the same agendas toward CSR do not engage each other. They keep duplicating each other projects without any considerations of the cost and impact created by these projects (ibid). The lack of collaboration was also reported among NGOs and charities as well as between NGOs and Ministry of Social Development, and between NGOs and companies with charitable activities (Hosni, personal interview, 2019; Ebrahim, personal interview, 2019).

\section{The Application of Inaccurate KPIs for CSR}

As a direct result of the weak awareness about CSR and sustainability concept and the associated misinterpretation of its dimensions, the governmental stakeholder, the practitioner companies, NGOs, and charities were unable to develop accurate KPIs to evaluate their own CSR/ sustainability performance or the performance of each other once applicable. For instance, many of the governmental stakeholders apply wrong KPIs for the social or community development initiatives they supervise (Alawi, personal interview, 2019). Moreover, NGOs and charities also face the same problem for being unable to set accurate KPIs for its activities which are all dependent on the financial and none financial support delivered by companies with CSR activities (ibid).

However, the application of inaccurate KPIs for CSR represents a more serious problem for the practitioner companies compared to other groups because that problem is also correlated with the problem of not applying any measures to CSR outputs by the majority of these companies. These two problems had again stemmed from the poor corporate awareness about CSR. For example, there are many companies that still regarding CSR as a cost center and therefore decide to keep their CSR expenditures minimized. Conversely, there are other companies that spend a lot of money to certain parties in the community just to secure their satisfaction regardless of how these parties would utilize the donated funds (Shukaili, personal interview, 2019). This is because these companies lack the proper awareness about the importance of measuring the impact of its financial contributions to the society or to report it on regular basis, or sometimes to keep it organized ( $\mathrm{H}$. Busaidi, personal interview, 2019). Therefore, many of these companies rely on basic quantitative KPIs that are poorly aligned with the declared social objectives (Masan, personal interview, 2019).

\section{Companies' Specific Challenges}

Companies in Oman as practitioners of CSR are facing multiple challenges that are mainly related to the internal business environment in addition to other external challenges imposed by other stakeholders such the government or the large society. As discussed in the previous section, the weak awareness about CSR values and best practices was the main cause of many challenges faced by different groups of stakeholders including the practitioner companies. 
Furthermore, many of these challenges are interrelated with each other or causing each other as will be clarified throughout the upcoming discussion.

\section{Immature Socially Responsible Corporate Culture and Executive Managements}

The traditional business culture that is highly profit-oriented still dominant among companies operating in the corporate sector in Oman including many of those with CSR or sustainability agendas. Therefore, CSR values and core subjects are usually communicated within a limited organizational scope such as the executive management level (Busaidi, personal interview, 2019).

As a result of the above mentioned poor sustainability/ CSR corporate culture, there is a weak awareness from executive managements in companies with CSR practices about the significance of CSR (Kashoob, personal interview, 2019). For instance, many of these managements' own tactic views toward CSR rather than strategic. This is reflected in their main concern to run the business with minimal expenses since they regard CSR as a cost item while profit generation remains their main focus. When they decided to practice certain types of CSR projects, each executive management specifies its own objectives based on its own understanding of the CSR concept. It was reported that these objectives are not based on any strategic or formal views that can be sustained on the corporate context (ibid). On another hand, that baseless CSR planning hinders companies' abilities to explore CSR potentials as driver for business innovation or to utilize companies' capabilities and resources to develop innovative CSR programs (Jabri, personal interview, 2019; Lawati, personal interview, 2019)

\section{Poor Communication of CSR/ Sustainability Objectives within Companies}

As another result for the poor corporate awareness about CSR and the weak social culture the practitioner companies have, CSR/ sustainability objectives and values are poorly communicated across these companies. The executive management at any particular company is the most responsible party to establish and motivate that communication across all organizational layers considering its position as the main social decision maker in that company. However, given that these managements lack the proper awareness about CSR essentials; the gap of communication between different parties within companies keeps expanding. For example, employees other than those handling CSR affairs or delivering CSR activities are completely kept out of the picture of their companies' CSR performances ( Lawati, personal interview, 2019). Furthermore, CSR is mainly communicated on activities' level rather than values or objectives. This is reflected in the process of engaging employees in the design of CSR initiatives suggested by these companies or as volunteers in the implementation phase of these activities. Therefore, it is not unusual to find many employees who lack awareness about CSR/ sustainability values held by their companies ( Kashoob, personal interview, 2019).

\section{Inconsistent Companies' Commitment to Behave Responsibly}

Beside the inconsistency in companies' support to CSR activities during tight economic conditions, there is also a more strategic concern related to the real commitment of these companies to behave responsibly under different executive managements regardless of the status of surrounding economic position. For example, the continuity of many companies in the Omani market in practicing CSR activities is usually correlated with the presence of executive managements that show strong interests to practice CSR. However, those interests 
are not translated as organizational values embedded in the companies' culture. Therefore, when these managements leave, all of the CSR agendas that had been practiced under its supervision vanish especially if the new managements do not own sufficient commitment to CSR as the departing managements (Zubaidi, personal interview, 2019). This is attributed to the absence of an organizational social culture embedded in the core values of these companies. Therefore, companies' CSR exercises become dependent on the commitment of acting leaders to behave responsibly.

\section{Miss-interpretation and Miss-application of CSR}

Lack of CSR awareness had also lead to the concept misinterpretation and miss-application by the practitioner companies. As an example of CSR miss-interpretation by companies, there are many companies that still mixing between CSR and donation and between CSR and marketing activities because they cannot figure out the exact difference between these themes (Lawati, personal interview, 2019). That intentional or unintentional miss-use of CSR as a marketing tool (Auffi, personal interview, 2019) is a direct result of the absence of the governmental guidance. However, companies who intentionally misuse the concept tend to use it as a pure marketing tool for their businesses and keep CSR as an extension of the marketing or public relations departments or within the main scope of these departments ( Sinani, personal interview, , 2019). In such cases, the ultimate aim of these companies is to achieve hidden marketing objectives through using CSR as a dressing mirror (Jabri, personal interview, 2019; Kashoob, personal interview, 2019; Sinani, personal interview, 2019).

Furthermore, CSR has been used as a tax incentive tool by many practitioner companies in response to Oman's Ministry of Finance acceptance to offer some tax incentives for companies with social contributions in terms of waiving taxation fees for any profit being utilized to fund the community development projects including CSR, grants, and donations to different parties in the local community (Balushi, personal interview, 2019). Therefore, this represents a direct motive for many companies in the market to practice CSR just to enjoy that incentive (Jabri, Personal Interview, 2019; Kashoob, personal interview, 2019).

Additionally, it has been reported that the societal satisfaction about companies' consideration to the society's needs and environmental concerns is very important for the success of these companies' businesses (S. Masan, personal interview, 2019). This is one of the key motives for some companies to miss-apply CSR as a tool to develop long term or immediate contractual relationships with the community or particular stakeholders such as government authorities. Companies feel securing positive relationships with the community or the government allow it to gain social legitimacy in the communities where it operates and also enjoy special recognition from the government. This strategy is more observed in companies with high environmental impacts such as those operating in the oil and gas sector that showed to be the activist in the CSR field in Oman compared to other companies with low environmental impact. These companies also pay high attention to fulfil the government requirements to mitigate the that high environmental impact through multiple means including developing the local communities where it operates (A. Kashoob, personal interview, 2019). Moreover, CSR is adopted by some companies to improve the business relationships with prospect customers in the large community. These customers are usually governmental entities that have a direct influence on companies' social decisions (ibid). 


\section{Direct Influence of Government on Companies' Social Decisions}

In addition to the influence of governmental customers on companies' decisions to practices CSR, the governmental influence is also practiced through other means. For example, the government business partners directly influence the type of CSR activities that these companies can do. This is clearly practiced by Ministry of Finance as the government representative in all government and semi-government owned companies. That influence has been remarked by all the participant companies from oil and gas sector in particular in addition to companies with governmental shareholding (S. Balushi, personal interview, October 1, 2019). On another hand, the government as a regulator has a direct influence on the decisions of companies operating under its umbrella to practice CSR. This is again case with the oil and gas sector where Ministry of Oil \& Gas has a direct impact on these companies' social decisions in general and the in-country-value (ICV) in particular. Furthermore, government as a main beneficiary of CSR is indirectly influencing the social investments made by social foundations or companies (Shizawi, personal interview, 2019; Kashoob, personal interview, 2019).

Improper stakeholders' engagement by companies:

The findings showed that companies' engagement of concerned stakeholders is tactical and periodic. The main purpose of that engagement is to facilitate the implementation of CSR programs initiated by these companies (A. Alawi, personal interview, October 16, 2019). In fact, that type of engagement does not contribute to establishing any strategic partnerships between companies and stakeholders to improve and expand the scope of CSR.

Again the absence of governmental guidance played a negative role on companies' engagement of stakeholders by reducing the quality of strategies undertaken by many of the socially responsible companies to set their own priorities to serve the community. These priorities are usually based on companies' judgment and/ or on assessment of impacts associated with their business operations but usually are not based on a wide strategic engagement of all concerned stakeholders since many of these companies lack the experience or the right vision to assess the stakeholders' interests. This has made many of them undertaking poorly designed CSR practices. The net result is the raise of many individual CSR initiatives that are almost unorganized, or of no common values to stakeholders. Furthermore, this plays an important role to restrict the expansion of CSR as strategy-based or sustainability oriented practice in Oman (Zubaidi, personal interview, 2019).

\section{Conclusion}

This paper explored challenges faced by CSR practitioner companies in Oman where CSR still in an infant stage. The findings showed the presence of commonly faced challenges shared between practitioner companies as well as other key stakeholders in general and the government in particular. These challenges were owning a poor awareness about CSR, lacking CSR policies and guiding framework, the absence of strategic partnership and collaboration between all stakeholders including the practitioner companies, and the application of inaccurate KPIs for CSR. Furthermore, the findings highlighted several companies-specific challenges that are mainly related to the internal business environment. These included; having corporate cultures and executive managements that are socially immature, poorly communicated CSR objectives inside companies, inconsistency in companies' commitment to behave responsibly, miss-interpretation and miss-application of CSR, direct influence of 
government on companies' social decisions, and companies' poor abilities to strategically engage stakeholders.

The aforementioned findings not only unveil challenges facing socially responsible companies in Oman but it contributed the practical knowledge on CSR in Oman by providing an advanced analysis of the nature of those challenges and highlighting the relationships between it.

\section{Future Studies}

Given the findings of this study, future researchers can suggest proposals to effectively resolve challenges hindering the application of CSR as a driver to sustainability by socially responsible companies in Oman.

\section{References}

Bowen, F. (2007). Corporate social strategy: Competing views from two theories of the firm. Journal of Business Ethics, 75(1), 97.

Choi, S. B., Ullah, S., M. E., \& Kwak, W. J. (2015). Ethical Leadership and Followers' Attitudes Toward Corporate Social Responsibility: The Role of Perceived Ethical Work Climate. Social Behavior \& Personality: An International Journal, 43(3), 353-365.

Goll, I., \& Rasheed, A. A. (2004). The moderating effect of environmental munificence and dynamism on the relationship between discretionary social responsibility and firm performance. Journal of Business Ethics, 49(1), 41.

Kim, S., Kim, J-N., \& Tam, L. (2016). Think socially but act publicly: refocusing CSR as corporate public responsibility. Journal of Public Affairs (14723891), 16(1), 91-104.

Macdonald, S. (2012). CSR needs more push. Times of Oman.

Mousiolis, D. T., \& Bourletidisa, K. (2014). The Corporate Identity through the CSR's Paths. Procedia - Social and Behavioral Sciences, 175, 511 - 514.

Mousiolis, D. T., \& Zaridis, A. D. (2014). The Effects in the Structure of an Organization through the Implementation of Policies from Corporate Social Responsibility (CSR). Procedia Social and Behavioral Sciences, 148, $634-638$.

Nollet, J., Filis, G., \& Mitrokostas, E. (2016). Corporate social responsibility and financial performance: A non-linear and disaggregated approach. Economic Modelling, 52, 400-407.

Prutina, Z. (2015). "DIAGNOSING THE CORPORATE SOCIAL RESPONSIBILITY CULTURE", Ekonomski Vjesnik, 28(2), 441-456.

Rosolen, T., \& Maclennan, M. L. F. (2016). Strategic human resource management and corporate social responsibility: Evidence from Emerging Markets. Internext: Revista Electrônica De Negócios Internacionais Da ESPM, 11(2), 66-80.

Shehadi, R., Ghazaly, S., Jamali, D., \& Jamjoom, M. (2013). The Rise of Corporate Social Responsibility: A Tool for Sustainable Development in the Middle East. Booz \& Company.

Szczuka, M. (2015). Social dimension of sustainability in CSR standards. Procedia Manufacturing, (3), $4800-4807$.

Vveinhardt, J., \& Zygmantaite, R. (2015). Influence of CSR Policies in Preventing Dysfunctional Behaviour in Organizations. Procedia - Social and Behavioral Sciences, 205, 340 - 348. 